\title{
The Consequences of Astroturf Lobbying for Trust and Authenticity. Findings and Implications from an Experiment
}

Original scientific paper _ DOI 10.22522/cmr20170121 _ received on 1 April 2017 UDK 328.184

\section{Irina Lock}

Amsterdam School of Communication Research, University of Amsterdam, The Netherlands. Email: lock@uva.nl (corresponding author)

\section{Peter Seele}

Università della Svizzera italiana, Lugano, Switzerland. Email: peter.seele@usi.ch

\section{Abstract}

In contrast to authentic grassroots activism, in astroturfing, lobbyists sponsor an interest group that pretends to be a grassroots movement. In a vignette-based experiment, we investigate for the first time how astroturfing, compared to grassroots lobbying, reflects on stakeholders' perceptions of organizational trust and authenticity, how perceived frequency of the practices relates to them, and the associations they trigger. Our results indicate that stakeholders perceive an astroturfing organization as barely trustful and authentic, even less so if the practice is perceived as occurring more frequently. Astroturfing triggered negative associations of manipulation. Such perceptions damage organizations' trustful relationships with their publics.

Keywords: astroturf lobbying, grassroots initiatives, trust, authenticity, public affairs 


\section{Introduction}

Public affairs (PA) textbooks for students and practitioners have ushered in a "golden age of grassroots lobbying" (Lerbinger, 2006, p. 252), as more traditional PA activities such as lobbying are deemed to be ineffective. When engaging in grassroots lobbying, the lobbyist supports an existing citizens' movement and contacts legislators via the voters, indirectly. This tactic has proven to be more effective than traditional lobbying because a politician is more prone to listen to his or her constituents than to a professional lobbyist. However, with this new era also comes the specious sister of grassroots lobbying, so-called astroturf lobbying (Lock et al., 2016).

Astroturfing is defined as "apparently grassroots-based citizen groups or coalitions that are primarily conceived, created and/or funded by corporations, industry trade associations, political interests or public relations firms" (Sourcewatch, 2013). A remarkable example of an astroturf lobbying campaign was discovered by an investigative journalist in Switzerland. Albeit the country is known for its direct democracy, this case shows how the deceptive astroturfing tactic can undermine democratic processes that are supposed to involve citizens directly into decision making: In 2013, Switzerland held a referendum about a fiercely discussed popular initiative labeled "Against Rip-off Salaries" ("Abzockerinitiative”). It foresaw the abolition of what is often referred to as "golden parachute" and "golden hello" packages that senior executives of corporations receive when leaving or entering a firm. In particular, the initiative aimed to abolish signing bonuses and termination payments for senior executives; moreover, it contained a ban on consultancy contracts with affiliated companies after a senior manager left the firm. The public appeared to favor the proposal, although the main interest group of the Swiss economy, Economiesuisse, invested eight million Swiss francs ${ }^{1}$ to fight it. It became even more popular as controversially discussed cases such as Novartis' ex-chief executive officer (CEO) Daniel Vasella, who received 72 million Swiss francs over six years for a noncompetition clause, hit the media.

During this time and a few weeks before the vote, a job announcement circulated at the University of Zurich: A student job agency was searching for politically interested students

1 Approximately 8.8 million US Dollar at the time of the referendum (approximate exchange rate March 2012 USD-CHF: 0.90 , see for instance: http://www.xe.com/currencycharts/?from=USD\&to=CHF \&view=5Y. 
to give their opinion on political topics online. The details read: Students should provide arguments to online articles that were in favor of "against rip-off salaries", open fake email accounts with unsuspicious names, pretend to be "critical citizens", and comment online against positive articles supporting the vote.

The job offer was published by a student job agency mandated by Werbeanstalt Schweiz, the PR agency leading the anti-vote campaign for Economiesuisse. However, Economiesuisse disclaimed that it had anything to do with the campaign. Instead, a co-owner of Werbeanstalt Schweiz and the head of the student job agency stated that they engaged the students on their own account. They believed that the public debate around the initiative had gotten out of control and needed some counter-fire to protect the industrial location of Switzerland. Whether this claim can be taken seriously remains in doubt in light of the interdependent relationships between principals and agents (Stäuble, 2012).

Even though astroturfing has been applied in public relations (PR) practice for many years as evident by the case presented above and practitioners' handbooks (Nownes, 2006), it has evoked sparse attention from researchers. Some have engaged in a theoretical discussion of the practice (Fitzpatrick, Palenchar, 2006; Irmisch, 2011; Greenberg, Knight, Westersund, 2011; Lyon, Maxwell, 2004; Cho et al., 2011; McNutt, Boland, 2007). However, to date no study has investigated empirically how astroturfing affects perceptions of the organization that pursues this strategy. Furthermore, research on the ethical dimension of the practice (Fitzpatrick, Palenchar, 2006) and on what it means for the theory of organization-public relations (OPR) is lacking.

Thus, this study sets out to examine how perceptions of astroturfing affect stakeholders' trust in the astroturfing organization and its perceived authenticity. These perceptions are compared to perceptions of grassroots activities. Furthermore, this research investigates whether levels of trust and authenticity in the lobbying organization vary with the perceived frequency of the strategy. Moreover, this is the first attempt to capture the top-of-mind associations of stakeholders when confronted with astroturfing and grassroots activities.

The data for this study are drawn from an experiment among 138 university students. The astroturf case around the "rip-off salaries" referendum and a manipulated ad-hoc scenario serve as a basis for the research. Data are analyzed quantitatively with parametric tests 
and qualitatively with thematic analysis. Findings reveal that trust in PA activities such as astroturfing and grassroots is essentially low. Participants perceive astroturfing organizations to be barely trustful and hardly authentic, while perception levels are higher for grassroots activism. Moreover, trust and authenticity levels vary by how frequently participants thought the lobbying practices occurred. Associations with regard to astroturfing are rather negative, referring to deception, doubt, or manipulation and triggering cynicism.

With this study, we attempt to make three major contributions. First, we illustrate empirically for the first time the effects of astroturf and grassroots lobbying on the organizations that pursue the activities. Second, we interpret these findings in light of OPR theory, the notion of trust in relationships, and legitimacy. Third, we address the ethical dimension of the strategy and what it means for PA practice.

The remaining parts of the paper proceed as follows: A literature review on grassroots and astroturf lobbying is followed by a theoretical section that outlines PR's role in building relationships, which also contains the hypotheses and research question. Afterward, the methods section details the sample and research procedure before the results are presented. In the discussion section, we combine the empirical findings with theory and outline implications for practice. Finally, we conclude and present limitations.

\section{Literature review}

\subsection{Grassroots and Astroturf Lobbying as PR Techniques}

PR operates at the crossing of business and society. One of these intersections is the political arena, where firms or other forms of organizations attempt "to produce public policy outcomes that are favorable to the firm's continued economic survival and success" (Keim, Baysinger, 1988, p. 172). Such activities are often summarized under the umbrella term public affairs, understood as " $[\mathrm{m}]$ anaging relationships between organisations and stakeholders/issues in the public policy (ie non-market or socio-political) environment" (Fleisher, 1994). Hence, PA encompasses an array of political activities, including donations, community relations, grassroots campaigns, and its specious sister astroturf lobbying (Thomson, John, 2007): "public affairs extends beyond the function of government relations alone" (Harris, Moss, 2001, p. 104). 
Traditional lobbying is an information strategy (Hillman, Hitt, 1999) defined as the "specialist part of PR that builds and maintains relations with government primarily for the purpose of influencing legislation and regulation" (Cutlip, Center, Broom, 1994, p. 17). It is usually targeted at legislators directly, giving constructive information input and providing knowledge expertise.

An indirect, constituency-building technique (Hillman, Hitt, 1999) to approach lawmakers is grassroots lobbying, which "involves engaging group members and/or others with a stake in an issue to persuade lawmakers to support the group's public policy goals" (Showalter, Fleisher, 2005, p. 110). Its intention is to "reach the folks back home" (McGrath, 2005, p. 97) as elected legislators depend on their constituents' support. The lobbyist may support an existing movement and urge more constituents to directly contact their politicians via email or telephone (Hawkinson, 2005). This indirect tactic renders grassroots lobbying highly effective because votes are the currency of every politician (Nownes, 2006). From the voters' perspective, grassroots lobbying offers a unique opportunity to participate in legislative processes and to bring their concerns and expertise into the public policy process. Hence, a grassroots movement is considered a credible and trustworthy form of bottom-up participation (McGrath, 2005).

This is probably why "the emergence of its Doppelganger - its ghostly, counterfeit twin: phony, synthetic, spurious 'grassroots' lobbying” (McGrath, 2005, p. 122) evokes increasing attention from researchers and the media. Coined astroturf lobbying, this strategy is characterized by "the instant manufacturing of public support for a point of view in which either uninformed activists or means of deception are used to recruit them" (Faucheux, 1995, p. 20). In practice, organizations sponsor or create an interest group that pretends to be a grassroots movement and thus fakes support from a large number of real people. The tricky part is that "fake grassroots organizations [...] may look and feel like they are community based, but [...] are created to manufacture the illusion of public or scientific skepticism or support for government or corporate policies and practices" (Greenberg et al., 2011, p. 70). Given that we live in a "golden age of grassroots lobbying" (Lerbinger, 2006, p. 252), its specious sister, astroturfing, is also on the rise, along with other strategies such as grasstops, where politicians are approached via people close to them (Lerbinger, 2006). This trend is accelerated by increasing digitalization and the shift of public discourse to the internet. Today, to implement an astroturfing strategy, 
PR firms may simply set up a supposedly grassroots-based website, create a "flog" (i.e., fake blog; McNutt, Boland, 2007), or engage in discussions with fake email identities.

Astroturf lobbying has been criticized even more than traditional lobbying for being an unethical practice pursued in the dark (Greenberg et al., 2011; Fitzpatrick, Palnchar, 2006). While traditional lobbyists take a constructive part in public policy processes by feeding in information (Grunig, Hunt, 1984) or deliberation (Lock, Seele, 2016), astroturfing organizations undermine democracy by faking grassroots movements. Astroturfing is thus considered an unethical practice pursued in the shadows. Actors are not only businesses with big money, but also non-profits (Fitzpatrick, Palenchar, 2006). From a PR point of view, this controversial technique is problematic as it threatens an organization's trustworthiness and authenticity through deception (Lyon, Maxwell, 2004; Cho et al., 2011). However, trust in organizations and trustful relationships with stakeholders are the basis for organizations' legitimacy in society and the central idea of PR (Heath, Waymer, Palenchar, 2013).

\section{Public Relations' Role in Building Relationships and the Issues of Trust and Authenticity in Astroturf Lobbying}

In fact, OPR theory has made the shift from regarding PR as a manipulative exercise toward an "emphasis on building, nurturing and maintaining organization-public relationships" (Kim, Chan-Olmsted, 2005, p. 145). Manipulation is the unethical face of persuasion, as it is a form of exercising power from one party over the other (Dickerson, 2012), which makes PR the voice of the more powerful party: "That voice, because of the competitive atmosphere of democracy, often escalates into shouting, arguing, grumbling and manipulating” (Heath et al., 2013, p. 278). OPR, instead, relies on relationship management (Ledingham, 2006), which has gained such a prominent position in theory that it has been called the "paradigm" of the practice (Heath, 2013, p. 426).

Accordingly, research has focused on the quality of stakeholder relationships because positive relations contribute to organizational effectiveness, loyalty, advocacy, crisis resolution, and stakeholders' goodwill, among others (Huang, 2001; Heath, 2013). As a consequence, PR is 
no longer evaluated by the content of messages alone, but also by the perceptions of these messages and of their senders (Kim, Chan-Olmsted, 2005). Thus, the perceived quality of stakeholder relationships has been measured by dimensions of reciprocity, trust, mutual legitimacy, openness, mutual satisfaction, and understanding (Grunig, Grunig, Ehling, 1992) and/or community involvement and reputation (Kim, 2001). Equal to these and other operationalizations is that trust in organizations is always a central component (Kim, ChanOlmsted, 2005). Relationships that are mutually trusting are important drivers of positive OPR and the fundaments of legitimacy: "[T]rust from publics enables an organization to exist" (Huang, 2001, p. 66f.).

Another interlinked concept that is central to OPR research and practice is perceived authenticity of the organization, which mediates between symmetrical communication and relationship quality (Shen, Kim, 2012). Authenticity is understood as "being true to oneself" (Edwards, 2010, p. 194); transferred to the behavior of organizations this means that they must act in a genuine manner and may not lie or deceive in their relations with stakeholders. In contrast to the outcomes of manipulation, "[b]eing seen as authentic means that your claim to membership in the field is valid" (Edwards, 2010, p. 199).

PA as a PR activity includes the management of multiple stakeholder relationships, with organizations on the one hand and politicians and constituents on the other (Harris, Moss, 2001). When it comes to non-traditional lobbying approaches, the role of community relations becomes even more prominent (Showalter, Fleisher, 2005). This is where spurious strategies such as astroturfing cause the most harm. Astroturf lobbying is considered an unethical practice (Gallicano, Brett, Hopp, 2013) because it undermines trust in the organization, harms its authenticity, and manipulates through the means of deception and lying. This may lead to irreversible mistrust in the organization on the side of stakeholders, which damages its legitimacy and may ultimately lead the public(s) to revoke its license to operate (Martin, Smith, 2008; Sweetser, 2010). Equally detrimental, astroturfing damages the trust in organizations engaging in real grassroots activities because the suspicion of phoniness wafts over real citizens' initiatives regarding worthwhile causes (Cho et al., 2011), which can ultimately threaten the functioning of democracy (Heath et al., 2013). As Fitzpatrick and Palenchar (2006, p. 206) put it: "Both approaches [grassroots and astroturf, here framed as coalitions and front groups] are widely used by organized interests, both are used by profit and 
nonprofit organizations and causes, both involve the utilization of financial resources, both involve the mobilization of human resources, and both rely on the development of public and behind-the-scenes political resources. However, coalitions do so in the light of day, exposing financial backers and causes. Front groups, on the other hand, are instruments designed to intentionally mislead the public and policymakers on policy matters."

In brief, "the key issue in all of this is trust" (McNutt, Boland, 2007, p. 169) and, we may add, organizations' authenticity (Shen, Kim, 2012). Hence, our first hypothesis reads:

H1. Organizations pursuing astroturf lobbying are perceived as less trustworthy than those engaging in grassroots lobbying.

In this vein, given the central role that authenticity plays in OPR:

H2. Organizations pursuing astroturflobbying are perceived as less authentic than those engaging in grassroots lobbying.

As most studies confirm, astroturfing is a common practice and part of the everyday toolbox of PR practitioners (Fitzpatrick, Palenchar, 2006; Cho et al., 2011). However, its covert nature makes it difficult or even impossible for stakeholders to discover (Lyon, Maxwell, 2004). Hence, we inquired whether astroturf and grassroots lobbying are perceived as a standard corporate practice by stakeholders. We may assume that if astroturf lobbying is perceived to be occurring as frequently as it de facto is, trust and authenticity levels are low and grassroots activities are under general suspicion of fraud (Hypotheses 3 and 4). To the best of our knowledge, no research to date has investigated the link between perceptions of the frequency of astroturfing and organizational trust and authenticity. Hence, hypotheses 3 and 4 read:

H3. The more frequent participants perceived astroturfing and grassroots to be, the less trust they displayed in the organization.

H4. The more frequent participants perceived astroturfing and grassroots to be, the less authentic they perceived the organization to be.

Digging deeper into the perceptions of astroturfing and addressing the call for more studies on its ethical dimension (Fitzpatrick, Palenchar, 2006), this study investigates the associations 
that stakeholders hold regarding the practice. We did not encounter studies that examine the associations that astroturf lobbying evokes in stakeholders, probably because such studies are difficult to conduct given that astroturfing usually occurs in the dark. Thus, we ask: $R Q$. What are participants' associations when confronted with astroturf lobbying?

\subsection{Method}

To test the research question and hypotheses, we conducted an online and in-class betweensubjects experiment in December 2014. The population consisted of 220 undergraduate business students from a German university. We chose a sample of business students because the scenario reflects the student and university context (student job agency) and is concerned with a lively debated issue in business courses, namely bonus payments. Thus, given that students took a major part in the astroturf case in reality, the students are the most suitable sample to test the hypotheses. The study was conducted in English; to check for adequate language proficiency, we followed a three-step procedure. First, we checked for how long participants had studied English at school. The result revealed that $94.2 \%$ of the participants had studied at least 6 years of English. To further control language proficiency, at the beginning, we asked participants for their English level and at the end how well they understood the survey. We deleted the cases in which participants indicated they had not understood the study. Last, we integrated comprehension questions regarding the scenario texts and controlled whether participants answered correctly. To further narrow down the sample to valid responses only, we deleted all that did not pass the software's built-in degradation indicator (> 150 points). After these procedures, the final sample consisted of 82 valid answers, for a response rate of $37.27 \%$.

The participants were randomly assigned to one of the two conditions and received an email with the link to the study minutes before the study started. Participants were given 20 minutes to complete the study on their electronic devices. To this end, we designed a laptop and a smartphone version. If participants could not attend class that day, they could participate from another location. Three days after class, we sent a reminder email to the participants who had not yet participated. 
The study was designed as follows. Participants were asked to read one of the two conditions; they had to remain on the page of the scenario for at least three minutes before they could move on to the next page to nudge them to read the scenario. Then, we triggered their first associations with an open text box. After that, we presented the scales of trust and authenticity before we asked for the perceived frequency of the practice. At the end, we surveyed sociodemographic data.

\subsection{Conditions}

To manipulate the two conditions, we created an ad-hoc scenario of the astroturfing case described below and based on it manipulated a second condition that depicts a grassroots case.

The astroturf vignette describes the lobbying case of the referendum "against rip-off salaries" mentioned in the introduction. The initiative aimed to abolish signing bonuses and termination payments for senior executives after cases of large payments to former executive officers became public and echoed negatively in the media (see appendix A for full vignette).

To compare this case of astroturf lobbying not only with its opposite, grassroots lobbying, we re-formulated the astroturfing scenario into a vignette describing a grassroots lobbying case. This method is widely used in communication research and also entered the field of PR (Alexander, Becker, 1978; Sohn, Lariscy, 2014; Pratt, Im, Montague, 1994). The grassroots scenario described the same referendum, but depicted a grassroots campaign, where a probusiness student association joined forces with the economy's interest group to influence public opinion with counter-arguments to the proposal (see appendix B for full vignette).

We anonymized the scenarios, such that participants were not disturbed by associations with the country: Switzerland was replaced by the fictional name "Ikmania", the interest group's and the agency's names were altered, and "against rip-off salaries" was changed to "stop boni”. Moreover, we neutralized the framing (see appendix for full scenarios).

The scenarios and the questionnaire were pre-tested with three colleagues for plausibility and feasibility. Two colleagues are junior scholars who have experience in vignette-based experiments; one colleague is a senior PR scholar. Their comments were mainly related to 
the design of the online experiment, for instance, they advised us to insert more text boxes to guide participants through the study. We also received comments on the design and understandability of the questions and scales, which we incorporated.

\subsection{Measures}

We used validated scales from the field of PR and advertising research to measure trust and perceived authenticity as the dependent variables in this single factor design.

Trust can be measured from quite different angles, such as psychology or interpersonal communication (Kim, Chan-Olmsted, 2005; Huang, 2001; Grunig, Grunig, Ehling, 1992). However, when applied to practices such as astroturfing, we refer to the notion that trust is based on cognitive elements, as the operationalization of trust in the ADTRUST scale shows (Soh et al., 2009). Here, trust is composed of three factors: perception of reliability, affect toward advertising, and willingness to rely on advertising. Following Kim and Chan-Olmsted (2005), we suggest that reliability perceptions are key when evaluating OPR; thus, we focus on trust as the perception of reliability, which includes the sub-dimensions of integrity and honesty (Soh et al., 2009). This scale consists of nine single-worded items measured on a 7-point Likert scale, which we adapted to the study's context by deleting one item ("complete"), because it did not fit the context of this study (see appendix C). The scale showed to be reliable (Cronbach's alpha $=0.88)$.

Authenticity was measured based on the organization's behavior by the perceived authentic organizational behavior scale (Shen, Kim, 2012). This scale consists of seven items that were slightly adapted to our context (e.g., we displayed the organization's values next to the respective item), measured on a 7-point Likert scale (see appendix $\mathrm{C}$ ). The scale was reliable $($ Cronbach's alpha $=0.81)$.

Perceived frequency was measured with a seven-point ("never" to "very often") scale asking: "how often do you think such practices occur in Germany in a year?".

The students' associations were analyzed using thematic analysis, a form of qualitative content analysis (Braun, Clarke, 2006). We used an inductive coding procedure and coded 
for emerging themes and patterns in the responses. Thematic categories emerged from the contents of the participants' comments, which were then clustered into broader themes. For instance, the themes "influence", "manipulation", and "misuse" appeared, which we clustered in a later step into "manipulation" only. Besides the contents, we also analyzed the tone of the responses: negative, neutral, positive, but also critical or skeptical.

We used SoSci Survey as the survey software; the quantitative results were analyzed with parametric tests using the software package SPSS.

\section{Results}

\subsection{Perceptions of Trust and Authenticity in Astroturf Lobbying}

Figure 1 shows the mean trust and authenticity levels for the two experimental conditions. Trust levels are overall lower than those of authenticity. The astroturfing organization is perceived as being barely trustful, with $M=2.82(S D=0.89)$. In contrast, the organization in the grassroots case is perceived as more trustful $(M=3.58, S D=0.99)$, even though the level of perceived trust is lower than the scale middle, pointing to an overall low perception of trust when it comes to these PA activities. An independent samples t-test revealed that the difference between levels of trust in astroturfing and grassroots is significant at $p<.00$ $(t(80)=-3.65)$. Hence, we can accept hypothesis 1 because organizations that pursue astroturf lobbying are perceived as less trustful than those engaging in grassroots lobbying.

We established that perceived authenticity of the organization's behavior is central to a positive organization-public relationship. Levels of perceived authenticity were consistently higher than those of perceived trust (above 3.00 for both cases). However, overall, the organization's behavior is still perceived as rather inauthentic. Furthermore, perceptions of the authenticity of the organization are on average higher when participants were confronted with the grassroots case $(M=3.74 ; S D=0.92)$ than when reading the astroturf scenario $(M=3.3, S D=1.07$; see Figure 1). This difference is with $p=.052(t(80)=-1.97)$ slightly above the significance level of $p=.05$. Thus, we cannot formally accept hypothesis 2 , but still observe a strong indication that organizations that pursue astroturf lobbying are perceived as being less authentic than those engaging in grassroots lobbying (see Figure 1). 


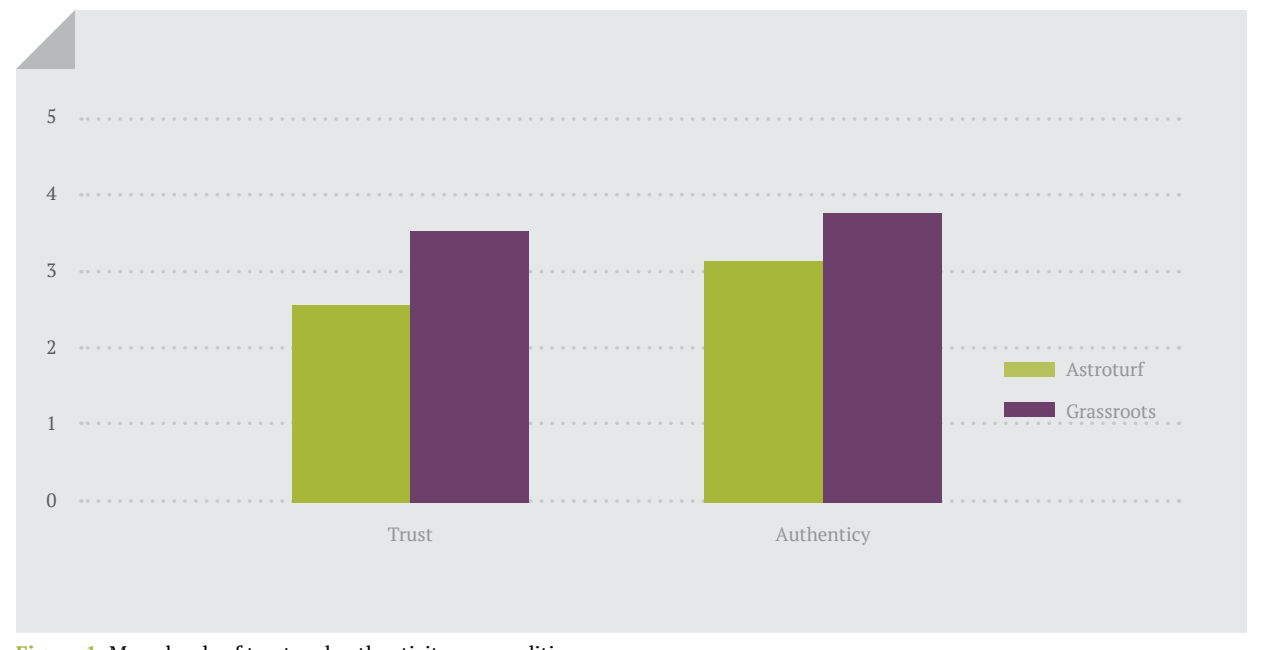

Figure 1: Mean levels of trust and authenticity per condition.

\subsection{Perceptions of Astroturf Frequency and Associations}

To explore whether astroturf and grassroots lobbying are perceived as standard corporate practices by stakeholders, we asked participants how often they thought such practices occurred in Germany in a year. Overall, participants held that astroturf and grassroots lobbying occur quite often in a year $(M=4.78, S D=1.57)$. In fact, the grassroots case is perceived as occurring rather often ( $M=4.93, S D=1.52)$, and for the astoturfing scenario, we find the same tendency $(M=4.62, S D=1.63)$. An independent samples t-test resulted in no significant difference between the two conditions with regard to frequency perceptions $(t(78)=-0.88, p$ $>$.05). Hence, stakeholders perceive PA activities such as astroturfing or grassroots lobbying as rather a standard practice in Germany. As a result, we analyze whether these perceptions of frequency vary with levels of trust and authenticity ( $\mathrm{H} 3$ and H4).

To test for H3, we performed a linear regression with trust as the dependent variable and frequency as the independent variable; the results were significant $\left(R^{2}=0.1, \beta=-0.31, t(1)\right.$ $=-2.87, p<.01)$. Thus, the perceived frequency of astroturfing and grassroots activities significantly negatively influences the levels of perceived trust in the organization; hence, $\mathrm{H} 3$ is accepted. The more frequent participants perceived these activities to be, the less trust they had in the organization, displaying a weakly negative significant relationship. Similar 
findings were obtained for perceptions of authenticity.

Authenticity as the dependent variable and frequency as the independent variable were put into a linear regression model to test for perceived authenticity (H4), which resulted significant $\left(R^{2}=0.09, \beta=-0.3, t(1)=-2.73 p<.01\right)$. As with trust, the more frequent participants perceived these practices to be, the less authentic they perceived the organizations to be; thus, we can accept H4. In brief, we found evidence that astroturfing organizations and grassroots lobbyers are perceived as less trustful and less authentic if participants think that these practices occur more frequently ( $\mathrm{H} 3$ and $\mathrm{H} 4)$.

The research question addresses participants' associations when confronted with astroturf or grassroots lobbying. We asked: "After having read and understood the text: What comes to your mind first?" Most first associations of the participants reading the grassroots case led to general remarks on boni and managers' pay, not directed toward the depicted PA practice or organization. Concerns about fairness were expressed twice in the grassroots case and the overall tone was mostly neutral.

On the contrary, the astroturf scenario evoked less general remarks. Instead, the themes manipulation and money emerged. For instance, the latter theme led one participant to ask: "Does money influence the result of a referendum?" Regarding the theme of manipulation, another participant wrote: "manipulation of citizens!” The astroturf scenario in general evoked less neutrally formulated first associations than the grassroots case and triggered more negatively and skeptically formulated responses. Interestingly, only in the astroturf case did participants also refer directly to lobbying. In general, we found that participants' first reactions to the astroturf and also the grassroots case were rather critical.

\subsection{Discussion}

Not only the media and researchers but also political institutions have paid attention to PA practices such as astroturfing. The European Commission (EC) remarked: "Concerns have been voiced [...] about lobbying practices which are considered to go beyond legitimate representation of interests. This applies not only to practices which are clearly unlawful (fraud and corruption) but also to other improper lobbying methods which abuse the EU 
[European Union] institutions' policy of openness or are plainly misleading” (EC, 2006, p. 5). Hence, astroturfing is not illegal per se, but it is regarded as unethical (Dahan et al., 2013). The product and brand AstroTurf was created to appear to be "real" grass in soccer and football stadiums. It does not grow naturally, but is installed artificially. Thus, it becomes a proper metaphor for a lobbying activity that is also not what it seems. In fact, this study resulted in interesting findings regarding the ethical dimension of astroturfing (Fitzpatrick, Palenchar, 2006) and how it affects the organizations pursuing this strategy in the eyes of stakeholders.

Our results indicate that stakeholders perceive organizations that engage in astroturfing as barely trustful and their behavior as barely authentic. Although organizations engaging in grassroots lobbying are perceived as more trustful and authentic, those levels still remain quite low. Such perceptions damage the organizations' relationships with publics. OPR builds on trust (Huang, 2001); if trust and authenticity are lacking due to an organization's PA activities, the organization will struggle to establish positive relationships with key stakeholders, which threatens the very nature of OPR. Positive relationships lead to organizational effectiveness (Huang, 2001) and are a means to establish and maintain an organization's license to operate in society (Heath et al., 2013). However, by engaging in illegitimate activities such as astroturfing, organizations gamble their legitimacy, which is central to PR (Waymer, Heath, 2014; Sweetser, 2010).

In the same vein, we observed that the grassroots organization was perceived as weakly trustful and authentic. This may be due to an overall high scrutiny and skepticism displayed by stakeholders toward PA. However, it might also be that the rise of astroturf lobbying led stakeholders to transfer their skepticism and low trust levels also toward authentic grassroots lobbying activism (Cho et al., 2011). If this is true, astroturf lobbying indeed "corrupts the policy-making process" (Greenberg et al., 2011, p. 70) and undermines democratic will formation, as reflected in the EC's quotation (EC, 2006).

Furthermore, participants in our study perceived astroturfing and grassroots lobbying as a rather standard practice, which has consequences for organizational trust and authenticity perceptions. The more frequent participants thought both practices to be, the less trust and authenticity they displayed toward the acting organizations. The nature of the practice, specious astroturfing or democratic grassroots lobbying, did not change participants' negative 
perceptions of trust and authenticity. We might conclude that the more frequent astroturfing and grassroots lobbying are, the more they harm democratic processes and practices, as those fall under general suspicion due to increased levels of skepticism.

This increased scrutiny is also reflected in the negative associations of participants with regard to astroturfing. The most frequent themes that emerged from the comments related to money and manipulation, the same as mentioned by researchers when referring to the practice (McNutt, Boland, 2007).

Thus, the consequences of astroturfing activities for organizations are detrimental, as we have proven empirically. Therefore, it impedes an organization's ability to build mutually trusting relationships. Over the long run, it may create "irreversible distrust" (Martin, Smith, 2008, p. 53) that threatens the notion of relationships and the positive outcomes of OPR. Ultimately, astroturfing jeopardizes an organization's legitimacy to operate in society. Grassroots lobbying, its democratic "sister", however, also resulted in low levels of trust and authenticity. Maybe this is because lobbying processes in general underlie high scrutiny or because activities such as astroturfing tainted organization-public relationships regarding political processes.

However, an abolition of astroturfing is unrealistic, simply because "front groups work" (Fitzpatrick, Palenchar, 2006, p. 221). Furthermore, it is not an illegal practice; regulation does not appear on the horizon. On the contrary, it seems that the strategy is further catalyzed by the mega trend of digitalization, which renders the implementation of astroturf strategies cheap and fast, for instance, through practices such as "ghost blogging” (Gallicano et al., 2013) or "flogs" (Martin, Smith, 2008). As McNutt and Boland (2007, p. 168) predicted: "The entire arsenal of e-marketing can be brought to bear on behalf of Astroturf efforts. The growing sophistication of these efforts is almost magical in nature."

As a consequence, it is even more important to make practitioners aware of the ethical dimension of astroturfing. Over the long run, astroturfing does not pay off, as it challenges stakeholders' trust in organizations and in democratic practices. Mutually trusting relationships will not be possible anymore if the already low levels of trust and authenticity are gambled through illegitimate and unethical behavior (Sweetser, 2010). If astroturfing continues to spread, stakeholders will react with "irreversible distrust". Then, at the least, OPR efforts will be pursued in vain. Hence, we follow Fitzpatrick and Palenchar (2006), who called for 
strengthening ethical guidelines of practitioners to prevent astroturfing activities. Otherwise, law makers eventually react to the activities of PA professionals with more fierce regulations: the European Commission and the Parliament issued a code of conduct that requires lobbyists to identify themselves and for whom they work. Non-compliance, as in the case of astroturfing, is sanctioned with temporary exclusion from the lobbying register, de facto denying access to all EU institutions (EC, 2011). According to the register's annual reports from 2012 to 2015, no lobbyist has been excluded from the register for breach of the identification clause (EC, 2017).

\section{Conclusions and Limitations}

To the best of our knowledge, this is the first attempt to empirically investigate perceptions of astroturf lobbying and their impact on organizational trust and authenticity. Our findings indicate that, overall, levels of perceived organizational trust and authenticity are quite low when it comes to astroturfing and only slightly higher with regard to grassroots movements. Stakeholders express doubt and associate manipulation and lobbying with astroturfing. The more astroturf lobbying is perceived as a standard practice, the less trust and authenticity is displayed toward the organizations behind such activities. These results reflect the specious nature of astroturfing in the eyes of stakeholders. We find that the effective pursuit of OPR is threatened if organizations maintain such practices, as they will put their legitimacy in society on the spot. Thus, we suggest refraining from this practice to maintain "dialogue at both a societal and government level” (Harris, Moss, 2001, p. 106).

This study is subject to at least the following limitations. We chose a well-documented astroturfing case that is close to participants' life reality. Thus, these results may not be readily generalized to other stakeholders or different contexts. However, the results provide an interesting first attempt to measure the effects of astroturf lobbying on public perceptions.

Furthermore, the measure for perceived frequency is not taken from previous research, but has been operationalized for the context of this study only. However, the three colleagues who pre-tested the study found that it is a comprehensible and clear scale and used properly in this analysis.

Moreover, the selection of the case for this study was not random. Random selection is almost 
impossible because astroturf activities are by nature pursued in the dark and therefore rarely documented. We deliberately chose an example from the academic context and from a different country to assuage direct associations. To test for grassroots perceptions as a control, we reformulated the astroturf scenario into a grassroots case. We did this in the common fashion of vignette-based experiments (Alexander, Becker, 1978).

We furthermore found that our participants are critical audiences, but lack comparison to other stakeholder groups. Perhaps students are even more critical than teachers in PR would think (L'Etang, 2006). This is why we suggest integrating (more) critical and ethical PR reflections into standard PR curricula.

\section{Reference List}

- Alexander, C. S., Becker, H. J. (1978). The use of vignettes in survey research. Public opinion quarterly, 42 (1), 93-104.

- Braun, V., Clarke, V. (2006). Using thematic analysis in psychology. Qualitative research in psychology, 3 (2), $77-101$.

- Cho, C. H., Martens, M. L., Kim, H., Rodrigue, M. (2011). Astroturfing global warming: It isn’t always greener on the other side of the fence. Journal of business ethics, 104 (4), 571-587.

- Cutlip, S., Center, A., Broom, G. (1994). Effective Public Relations. Englewood Cliffs, NJ: Prentice-Hall.

- Dahan, N. M., Hadani, M., Schuler, D. A. (2013). The governance challenges of corporate political activity. Business \& Society, 52 (3), 365-387. DOI: 10.1177/0007650313491470.

- Dickerson, A. (2012). What's Wrong with Asymmetry? Persuasion and Power in Public Relations Theory. Prism, 9 (2). Retrieved from: http://www.prismjournal.org/fileadmin/9_2/Dickerson.pdf. July 15, 2017.

- Edwards, L. (2010). Authenticity in organisational context: fragmentation, contradiction and loss of control. Journal of Communication Management, 14 (3), 192-205.

- European Commission - EC. (2017). Annual Reports. Retrieved from http://ec.europa.eu/transparencyregister/public/ staticPage/displayStaticPage.do?locale=en \&reference=ANNUAL_REPORT. July 15, 2017.

- European Commission - EC. (2011). Agreement between the European Parliament and the European Commission on the establishment of a transparency register for organisations and self-employed individuals engaged in EU policy-making and policy implementation. Brussels, $22^{\text {nd }}$ July, L 191/29.

- European Commission - EC. (2006). Green Paper European Transparency Initiative. Brussels, 3rd of May, COM (2006) 194 final. Retrieved from: http://europa.eu/documents/comm/green_papers/pdf/com2006_194_en.pdf. July 15, 2017.

- Faucheux, R. (1995). The grassroots explosion. Campaigns \& Elections, 16, 20-27.

- Fitzpatrick, K. R., Palenchar, M. J. (2006). Disclosing special interests: Constitutional restrictions on front groups. Journal of Public Relations Research, 18 (3), 203-224.

- Fleisher, C. (1994). Leading-Edge Measurement and Evaluation Ideas for Managing Public Affairs. In: Shafer, P. (Ed.), Adding Value to the Public Affairs Function (pp. 123-132). Washington, DC: Public Affairs Council.

- Gallicano, T. D., Brett, K., Hopp, T. (2013). Is ghost blogging like speechwriting? A survey of practitioners about the ethics of ghost blogging. Public Relations Journal, 7 (3), 1-41.

- Greenberg, J., Knight, G., Westersund, E. (2011). Spinning climate change: Corporate and NGO public relations strategies in Canada and the United States. International Communication Gazette, 73 (1-2), 65-82.

- Grunig, L. A., Grunig, J. E., Ehling, W. P. (1992). What is an effective organization? Excellence in Public Relations and Communication Management. Hillsdale, NJ: Lawrence Erlbaum Associates.

- Grunig, J. E., Hunt, T. (1984). Managing Public Relations. New York: Holt, Rinehart and Winston.

- Harris, P., Moss, D. (2001). In search of public affairs: A function in search of an identity. Journal of public affairs, 1 (2), $102-110$.

- Hawkinson, B. (2005). The internal environment of Public Affairs: Organization, Process and Systems. In: Harris, P., Fleisher, 
C. S. (Eds.), The Handbook of Public Affairs (pp. 76-85). Thousand Oaks, CA: Sage.

- Heath, R. L. (2013). The journey to understand and champion OPR takes many roads, some not yet well traveled. Public Relations Review, 39 (5), 426-431.

- Heath, R. L., Waymer, D., Palenchar, M. J. (2013). Is the universe of democracy, rhetoric, and public relations whole cloth or three separate galaxies? Public Relations Review, 39 (4), 271-279.

- Hillman, A. J., Hitt, M. A. (1999). Corporate political strategy formulation: A model of approach, participation, and strategy decisions. Academy of management review, 24 (4), 825-842.

- Huang, Y. H. (2001). OPRA: A cross-cultural, multiple-item scale for measuring organization-public relationships. Journal of Public Relations Research, 13 (1), 61-90.

- Irmisch, A. (2011). Astroturf: eine neue Lobbyingstrategie in Deutschland? Heidelberg, Germany: Springer-Verlag.

- Keim, G., Baysinger, B. (1988). The efficacy of business political activity: Competitive considerations in a principal-agent context. Journal of Management, 14 (2), 163-180.

- Kim, Y. (2001). Searching for the organization-public relationship: a valid and reliable instrument. Journalism and Mass Communication Quarterly, 78 (4), 799-815.

- Kim, J., Chan-Olmsted, S. M. (2005). Comparative effects of organization-public relations and product-related attributes on brand attitude. Journal of Marketing Communications, 11 (3), 145-170.

- Ledingham, J. A. (2006). Relationship management: A general theory of public relations. In: Botan, C. H., Hazleton, V. (Eds.), Public relations theory II, (pp. 465-483). New York: Lawrence Erlbaum.

- L'Etang, J. (2005). Critical public relations: Some reflections. Public Relations Review, 31 (4), 521-526.

- Lerbinger, O. (2006). Corporate public affairs: Interacting with interest groups, media, and government. London, UK: Routledge.

- Lock, I., Heath, R., Seele, P. (2016). Where grass has no roots: The concept of 'shared strategic communication' as an answer to unethical astroturf lobbying. International Journal of Strategic Communication, 10 (2), 87-100. DOI: 10.1080/1553118X.2015.1116002.

- Lock, I., Seele, P. (2016). Deliberative Lobbying: Toward a Non-Contradiction of Corporate Political Activities and Corporate Social Responsibility. Journal of Management Inquiry, 25 (4), 415-430. DOI: 10.1177/1056492616640379.

- Lyon, T. P., Maxwell, J. W. (2004). Astroturf: Interest group lobbying and corporate strategy. Journal of Economics \& Management Strategy, 13 (4), 561-597.

- Martin, K. D., Smith, N. C. (2008). Commercializing social interaction: The ethics of stealth marketing. Journal of Public Policy \& Marketing, 27 (1), 45-56.

- McGrath, C. (2005). Lobbying in Washington, London, and Brussels: The persuasive communication of political issues. Lewiston, NY: Edwin Mellen Press.

- McNutt, J., Boland, K. (2007). Astroturf, technology and the future of community mobilization: Implications for nonprofit theory. Journal of Sociology \& Social Welfare, 34, 165.

- Nownes, A. J. (2006). Total lobbying: What lobbyists want (and how they try to get it). New York: Cambridge University Press.

- Pratt, C. B., Im, S., Montague, S. N. (1994). Investigating the application of deontology among US public relations practitioners. Journal of Public Relations Research, 6 (4), 241-266.

- Shen, H., Kim, J.-N. (2012). The Authentic Enterprise: Another Buzz Word, or a True Driver of Quality Relationships? Journal of Public Relations Research, 24 (4), 371-389.

- Showalter, A., Fleisher, C. S. (2005). The tools and techniques of public affairs. In: Harris, P., Fleisher, C. S. (Eds.), The Handbook of Public Affairs (pp. 109-122). Thousand Oaks, CA: Sage.

- Soh, H., Reid, L. N., King, K. W. (2009). Measuring trust in advertising. Journal of Advertising, 38 (2), 83-104.

- Sohn, Y. J., Lariscy, R. W. (2014). Understanding reputational crisis: Definition, properties, and consequences. Journal of Public Relations Research, 26 (1), 23-43.

- Sourcewatch (2013). Astroturf. Retrieved from http://www.sourcewatch.org/index.php/Astroturf. July 15, 2017.

- Stäuble, M. (2012). Wie die Gegner der Abzockerinitiative die Debatte manipulieren. Tages-Anzeiger, 29th December. Retrieved from http://www.tagesanzeiger.ch/schweiz/standard/Wie-Gegner-der-Abzockerinitiative-die-Debatte-manipulieren/ story/22791059. July $15,2017$.

- Sweetser, K. D. (2010). A losing strategy: The impact of nondisclosure in social media on relationships. Journal of Public Relations Research, 22 (3), 288-312.

- Thomson, S., John, S. (2006). Public affairs in practice: a practical guide to lobbying. London, UK: Kogan Page Publishers.

- Waymer, D., Heath, R. L. (2014). Organisational legitimacy: The overlooked yet all-important foundation of OPR research. Prism, 11 (2). Retrieved from: http://www.prismjournal.org/homepage.html. July 15, 2017.

- XE Currency Charts (n.d.) Retrieved from: http://www.xe.com/currencycharts/?from=USD\&to=CHF \&view=5Y. July $18,2017$. 


\section{Appendices}

\section{Appendix A: Astroturf Scenario}

\section{"Stop boni"}

In 2013, the European country Ikmania held a referendum about a controversial popular initiative labeled STOP BONI. It sought the abolition of what is often referred to as "golden parachute" and "golden hello" compensation packages that senior executives of big companies receive when entering or leaving a firm. The initiative aimed to abolish signing bonuses and termination payments for senior executives; moreover, it contained a ban of consultancy contracts with affiliated companies when the senior manager left the firm.

The main interest group of the country's economy, IKMANIAN-ECONOMY, invested eight million Euros to fight this initiative. IKMANIAN-ECONOMY states on its website: "Our mission is to create an optimal economic environment for Ikmanian business. To achieve this, we aim to preserve entrepreneurial freedom for all businesses, to continuously improve Ikmania's global competitiveness in manufacturing, services, and research, and to promote sustained growth as a prerequisite for a high level of employment in Ikmania".

A few weeks before the official vote, opinion polls revealed that the Ikmanian public appeared to be in favor of the proposal. Around that time, a job announcement circulated at Ikmania's main university: a student job agency searched for politically interested students. The agency called for students who were willing to state an opinion on political topics online. Detailed instructions were given: students should provide counterarguments to online articles supporting the STOP BONI referendum through email accounts set up with "unsuspicious" names. Furthermore, the students should pretend to be "critical citizens" that comment online against articles that are in favor of STOP BONI.

The job offer was published by a student job firm mandated by PUBLICITY, the PR agency leading the anti-vote campaign for IKMANIAN-ECONOMY. However, IKMANIAN-ECONOMY denied that it had anything to do with the campaign. Instead, a co-owner of PUBLICITY and the head of the student job agency claimed to have engaged the students on their own accounts. They found that the public debate around the initiative got out of control and therefore felt obliged to act against the referendum. Thus, they claimed to have hired students to counterfire the initiative publicly and thereby to protect the industrial location of Ikmania. 


\section{Appendix B: Grassroots Scenario}

\section{"Stop boni"}

In 2013, the European country Ikmania held a referendum about a controversial popular initiative labeled STOP BONI. It sought the abolition of what is often referred to as "golden parachute" and "golden hello" compensation packages that senior executives of big companies receive when entering or leaving a firm. The initiative aimed to abolish signing bonuses and termination payments for senior executives; moreover, it contained a ban of consultancy contracts with affiliated companies when the senior manager left the firm.

The main interest group of the country's economy, IKMANIAN-ECONOMY, invested eight million Euros to fight this initiative. IKMANIAN-ECONOMY states on its website: "Our mission is to create an optimal economic environment for Ikmanian business. To achieve this, we aim to preserve entrepreneurial freedom for all businesses, to continuously improve Ikmania's global competitiveness in manufacturing, services, and research, and to promote sustained growth as a prerequisite for a high level of employment in Ikmania”.

The issue was also discussed controversially at universities and in student circles. At Ikmanian's largest university, the business students' association BSI (Business Students for Ikmania) published a position paper stating that the referendum disadvantaged the industrial location of Ikmania and its competitive position in Europe, because corporations were prevented from paying competitive compensation packages.

Hereupon until the vote was cast, the organization IKMANIAN-ECONOMY partnered with BSI to join forces against STOP BONI. Together and openly they established a website with counterarguments, gave talk show interviews, and wrote opinion letters to major newspapers. In the end, the Ikmanian public voted in favor of the initiative. Thus, since 2013, Ikmanian corporations may not pay "golden hello" or "golden parachute” packages to executives any more. 


\section{Appendix C: Scales}

ADTRUST scale - dimension perception of reliability (Soh et al., 2009)

Single worded items on seven-point Likert scale.

"Based on your first impression, please rate on a scale from 1 (not at all) to 7 (very much so) whether you think that [name of organization] is:"

Honest

Truthful

Credible

Reliable

Dependable

Accurate

Factual

Clear

Perceived authentic organizational behavior scale (Shen, Kim, 2012)

Seven items measured on a seven-point Likert scale.

"Based on your first impression, please rate the following statements regarding [name of organization] on a scale from 1 (totally disagree) to 7 (totally agree):”

This organization always tells the truth.

I believe that this organization's actions are genuine.

I feel that this organization is willing to admit to mistakes when they are made.

I feel that this organization accepts and learns from mistakes.

I believe that this organization's behavior matches its core values.

The organization's beliefs and actions are consistent.

I think this organization matches the rhetoric with its action. 


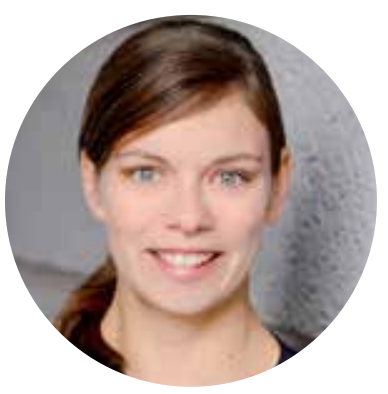

\section{Irina Lock}

Irina Lock is assistant professor of corporate communication at the University of Amsterdam, the Netherlands. Her research interests cover corporate social responsibility (CSR) communication, digital corporate communication, and public affairs.

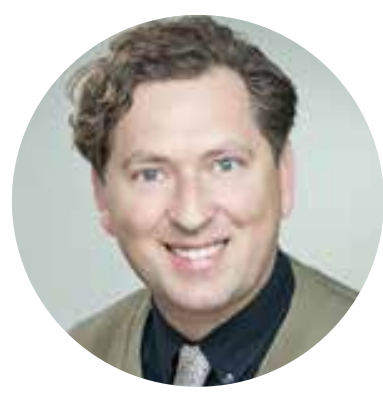

\section{Peter Seele}

Peter Seele is associate professor of CSR and business ethics at the Università della Svizzera italiana, Lugano, Switzerland. His research focuses on CSR reporting, CSR and digitalization, and ethics and the law. 